\title{
Great auricular neuropraxia with beach chair position
}

\section{Minal Joshi' \\ Ruth Cheng ${ }^{2}$ \\ Hattiyangadi Kamath' \\ Joel Yarmush'}

'Department of Anesthesiology, New York Methodist Hospital, New York, NY, USA; ${ }^{2}$ School of Medicine, St. George's University, Grenada, West Indies

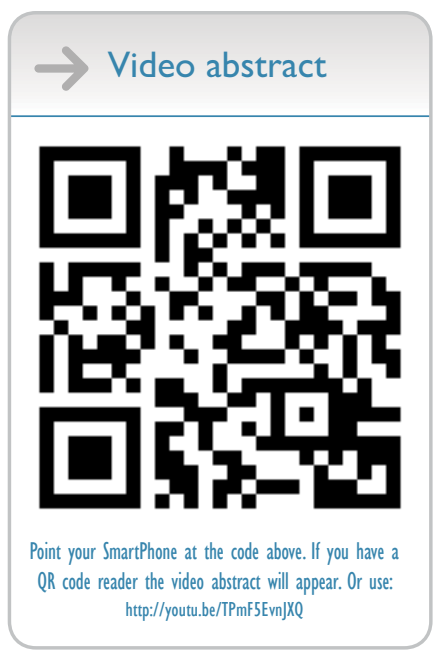

Correspondence: Minal Joshi

Department of Anesthesiology, New York Methodist Hospital, 506, 6th Street, Brooklyn, NY II 215 , USA

$\mathrm{Tel}+\mathrm{I} 7187803279$

$\mathrm{Fax}+\mathrm{I} 7187803281$

Email minuday2000@gmail.com
This article was published in the following Dove Press journal:

Local and Regional Anesthesia

20 July 2017

Number of times this article has been viewed

Abstract: Shoulder arthroscopy has been shown to be the procedure of choice for many diagnostic and therapeutic interventions. Neuropraxia of the great auricular nerve (GAN) is an uncommon complication of shoulder surgery, with the patient in the beach chair position. We report a case of great auricular neuropraxia associated with direct compression by a horseshoe headrest, used in routine positioning for uncomplicated shoulder surgery. In this case, an arthroscopic approach was taken, under regional anesthesia with sedation in the beach chair position. The GAN, a superficial branch of the cervical plexus, is vulnerable to neuropraxia due to its superficial anatomical location. We recommend that for the procedures of the beach chair position, the auricle be protected and covered with cotton and gauze to avoid direct compression and the position of the head and neck be checked and corrected frequently.

Keywords: neuropraxia, anesthesia, arthroscopy, great auricular nerve

\section{Introduction}

Arthroscopy has become the procedure of choice for many diagnostic and therapeutic shoulder surgeries. ${ }^{1}$ A recent study using the 2006 National Survey of Ambulatory Surgery found that an estimated 257, 541 shoulder arthroscopies (excluding rotator cuff) were performed in the USA in $2006 .{ }^{2}$ The most common indications for noncuff repair shoulder arthroscopy included impingement syndrome, periarthritis, bursitis, and instability. ${ }^{2}$ Complications have been reported with shoulder arthroscopy in beach chair position, including reduced cerebral perfusion, loss of vision, stroke, opthalmoplegia, stretching of brachial plexus, and abnormal pressure to heels and knees, ${ }^{3}$ upper extremity deep vein thrombosis, ${ }^{4}$ tracheal compression caused by extravasation of irrigation fluid in the upper airway, ${ }^{3}$ as well as neuropraxia of the great auricular nerve (GAN). ${ }^{5}$ We report a case of neuropraxia in the GAN associated with direct compression using a horseshoe headrest while in the beach chair position.

\section{Case presentation}

A 55-year-old female with a past medical history of degenerative spondylosis of $\mathrm{C} 4$, C5, and C6, obesity, hypertension, gastro esophageal reflux disease, osteoarthritis, asthma, hypertrophic lichen planus, and eczema underwent a right shoulder arthroscopy and rotator cuff repair under regional anesthesia. Interscalene block was performed with $20 \mathrm{cc}$ of $0.5 \%$ ropivicaine plus $20 \mathrm{cc}$ of $2 \%$ lidocaine under ultrasound guidance and nerve stimulator technique after negative aspiration of blood on the right side. The tip of the needle was visualized with ultrasound at the appropriate site for nerve 
block. There was no twitch at $0.2 \mathrm{~mA}$ before the injection of the local anesthetic. Care was taken to avoid pressure on internal structures. The patient was comfortable throughout the procedure. She remained in the beach chair position for 143 minutes during the procedure - from draping to closure under sedation. Perioperatively, positioning was checked for tightness and pressure of the headrest.

The patient had an uneventful recovery and was subsequently discharged. During the call back follow-up, the patient described numbness in the lobule of her left ear extending to her left mandibular angle. MRI studies of the head and neck were performed and revealed no significant abnormalities that could explain the symptoms. Injury of the GAN was suspected as it was on the contralateral side of the procedure. After 5 months, her symptoms were still present but decreased in intensity.

\section{Discussion}

Shoulder arthroscopy has been performed in either the beach chair position or the lateral decubitus position for better access to surgical site. There have been no studies that report objective evidence to support whether the beach chair position is superior to the lateral decubitus position. ${ }^{6}$ Positioning of the patients during shoulder arthroscopy is often chosen according to orthopedic surgeon preference. ${ }^{3}$ Beach chair position is preferred for the upright orientation of patients that allows ease of teaching during surgical procedure. However, this position has also been reported with fogging of camera and collection of bubbles in the subacromial space that reduces visibility. ${ }^{3}$ Complications have been reported with shoulder arthroscopy in the beach chair position, such as reduced cerebral perfusion, loss of vision, stroke, opthalmoplegia, stretching of brachial plexus, and abnormal pressure to heels and knees, ${ }^{3}$ upper extremity deep vein thrombosis, ${ }^{4}$ tracheal compression caused by extravasation of irrigation fluid in the upper airway, ${ }^{3}$ as well as neuropraxia of the GAN. ${ }^{6}$ Here, we report a case of neuropraxia in the GAN associated with direct compression using a horseshoe headrest while in the beach chair position. The diagnosis of the GAN in our case report was based on clinical symptoms and anatomical location of symptoms. No studies have reported the role of electromyography or imaging such as MRI or CT for definitive diagnosis. Often, MRI of the head and neck is used for diagnosing exclusion and for identifying organic causes such as brainstem infarction $^{7}$ and muscular or subcutaneous abnormalities.

The cervical plexus has muscular and cutaneous branches. The muscular branch comprises the ansa cervicalis and the phrenic nerve. The cutaneous branch comprises the GAN, the transverse cervical nerve, the lesser occipital nerve, and the supraclavicular nerve. The GAN, a sensory branch of the cervical plexus, arises from $\mathrm{C} 2$ to $\mathrm{C} 3$ and exits posterior to the sternocleidomastoid $\sim 1 \mathrm{~cm}$ below the spinal accessory nerve. ${ }^{5}$ The main trunk of the GAN then branches out and supplies sensation to the lobule, concha, and posterior auricle as well as the angle of the mandible, the parotid gland, and the parotid fascia. A dissection study on the GAN has given anatomical evidence on where this nerve can be injured. ${ }^{5}$ The GAN is shown to be predictably identified coursing between the inferior auricular and subauricular compartments. Identification of the anatomical course of the GAN prior to surgery may prevent injury intraoperatively. In addition, McKinney's point is the location where the main trunk of the GAN dives beneath Lore's fascia and the tail of the parotid. Below McKinney's point, the nerve lies more superficially to the skin, where it is covered only by fat superficial to the deep cervical fascia. Here, the GAN is most at risk for compression injury. The lesser occipital nerve, another cutaneous ascending branch of $\mathrm{C} 2$ and $\mathrm{C} 3$, curves around and ascends the posterior border of the sternocleidomastoid. It then perforates the deep fascia and ascends to the side of the head behind the auricle, supplying the posterior part of the upper neck as well as the scalp posterior to the auricle. Additionally, it gives off an auricular branch that supplies the skin of the upper and posterior part of the auricle. Like the GAN, the lesser occipital nerve is also at risk for compression due to its superficial course.

Studies have reported neurological complications ranging from cutaneous neuropraxia to complete midcervical quadriplegia related to incorrect head positioning during surgery. GAN and lesser occipital nerve neuropraxia in patients after arthroscopic shoulder surgery in the beach chair position have been reported due to prolonged compression of the nerves from the headrest holder. ${ }^{8}$ Thus, the authors recommend extra-auricular padding and frequent head position checks throughout surgery to avoid complications in the future. While we did not report hypoglossal nerve damage, hypoglossal nerve palsy after shoulder hemiarthroplasty in beach chair position in relation to incorrect head positioning as well as intubation has also been reported..$^{9-11}$ Pariente et al reported a patient showing 4 weeks of right hypoglossal nerve paralysis that then resolved without permanent damage. ${ }^{10}$ The author attributed hyperextension of the neck during intubation, endotracheal tube cuff pressure, excessive hyperextension, or head lateralization during surgery as possible causes of hypoglossal nerve damage intraoperatively. 
Similarly, Cogan et al reported a case of neuropraxia of the 9th, 10th, and 12th cranial nerve pairs after rotator cuff repair in the beach chair position, possibly because of intubation or positioning of the head intraoperatively. ${ }^{11}$ Last, the most serious complication reported was spinal cord infarction and midcervical quadriplegia in patients who underwent surgery in the upright-seated position. ${ }^{7}$ The author attributed the spinal cord injury to extreme neck flexion that eventually led to ischemia of the spinal cord. While extreme flexion of the neck is uncommon in shoulder surgery, surgeons should take special care of head positioning during procedure to avoid serious complications postoperatively.

The GAN, a branch of the cervical plexus, is vulnerable to neuropraxia secondary to direct compression due to its anatomical positioning. We recommend that care be taken to protect the auricle against compression with extra padding of the headrest to minimize pressure. We also recommend frequent monitoring of the head position throughout surgery and for repositioning as necessary to avoid possible compression-induced neuropraxia.

\section{Acknowledgments}

Written informed consent was obtained from the patient for publication of the case details. The authors thank Dr Joseph SchianodiCola, Chairman, Department of Anesthesiology, New York Methodist Hospital, for providing general support to write this paper.

\section{Disclosure}

The authors report no conflicts of interest in this work.

\section{References}

1. Wolf JM, Dukas A, Pensak M. Advances in wrist arthroscopy. $J$ Am Acad Orthop Surg. 2012;20(11):725-734.

2. Jain NB, Higgins LD, Losina E, Collins J, Blazar PE, Katz JN. Epidemiology of musculoskeletal upper extremity ambulatory surgery in the United States. BMC Musculoskelet Disord. 2014;15:4.

3. Ozhan MO, Suzer MA, Cekmen N, Caparlar CO, Eskin MB. Tracheal compression during shoulder arthroscopy in the beach-chair position. Curr Ther Res Clin Exp. 2010;71(6):408-415.

4. Durant TJ, Swanson BT, Cote MP, Allen DA, Arciero RA, Mazzocca AD. Upper extremity deep venous thromboembolism following arthroscopic labral repair of the shoulder and biceps tenodesis: a case report. Int $J$ Sports Physical Therapy. 2014;9(3):377-382.

5. Rohrich R, Taylor NS, Ahmad J, Lu A, Pessa J. Greater auricular nerve injury, the "subauricular band" phenomenon, and the periauricular adipose compartments. Plast Reconst Surg. 2011;127(2):835-843.

6. Peruto CM, Ciccotti MG, Cohen SB. Shoulder arthroscopic position: lateral versus beach chair. Arthroscopy. 2009;25(8):891-896.

7. Morandi X, Riffaud L, Amlashi SF, Brassier G. Extensive spinal cord infarction after posterior fossa surgery in the sitting position: case report. Neurosurgery. 2004;54(6):1512-1515.

8. Park TS, Kim YS. Neuropraxia of the cutaneous nerve of the cervical plexus after shoulder arthroscopy. Arthroscopy. 2005;21(5):631.

9. Rhee YG, Cho NS. Isolated unilateral hypoglossal nerve palsy after shoulder surgery in beach-chair position. J Shoulder Elbow Surg. 2008;17(4):e28-e30.

10. Pariente L, Camarena P, Koo M, Sabete A, Armengo J. Hypoglossal nerve neuropraxia after shoulder hemiarthroplasty. Rev Esp Anestesiol Reanim. 2014;61(5):277-280.

11. Cogan A, Boyer P, Soubeyrand M, Hamida FB, Vannier JL, Massin P. Cranial nerves neuropraxia after shoulder arthroscopy in beach chair position. Ortho Traumatol Surg Res. 2011;97(3):345-348.
Local and Regional Anesthesia

\section{Publish your work in this journal}

Local and Regional Anesthesia is an international, peer-reviewed, open access journal publishing on the development, pharmacology, delivery and targeting and clinical use of local and regional anesthetics and analgesics. The journal is included in PubMed, and welcomes submitted papers covering original research, basic science, clinical studies,

\section{Dovepress}

reviews and evaluations, guidelines, expert opinion and commentary, case reports and extended reports. The manuscript management system is completely online and includes a very quick and fair peer-review system, which is all easy to use. Visit http://www.dovepress.com/ testimonials.php to read real quotes from published authors. 